\title{
Restin suppressed epithelial-mesenchymal transition and tumor metastasis in breast cancer cells through upregulating mir-200a/b expression via association with p73
}

Zhenduo $\mathrm{Lu}^{1+}$, Dechuang Jiao ${ }^{1 \dagger}$, Jianghua Qiao', Sen Yang ${ }^{2}$, Min Yan', Shude Cuil ${ }^{1 *}$ and Zhenzhen Liu ${ }^{1 *}$

\begin{abstract}
Background: Restin belongs to MAGE superfamily and is known as MAGE H1. Restin was firstly cloned from HL-60 cells treated with all-trans retinoic acid (ATRA). Previous studies showed a pro-apoptotic role of Restin in several cell lines. However, little information is available on its expression patterns and functions in vivo. Our study was performed to detect if Restin plays a role in breast cancer cells in vitro and in vivo.

Methods and results: Real-time PCR and western blot were conducted to detect Restin expression in multiple breast cancer cell lines and Restin level was negatively related with cell motility. Restin overexpression and knockdown stable cell lines were established by transducing lentivirus into MCF-7 and MDA-MB-231 cells. Cell morphology, wound closure assay, transwell migration and invasion assays were performed to detect if Restin inhibited EMT. Our data showed that Restin overexpressed cells exhibited classical epithelial cell morphology, and Restin overexpression resulted in activation of epithelial markers and suppression of mesenchymal markers, and inhibition of cell migration and invasion. Tumor xenograft model was used to characterize the biological functions of Restin in vivo. We found that Restin overexpression led to reduced lung metastasis. Real-time PCR, western blot, luciferase assay and ChIP assay were performed to identify the potential targets of Restin and the underlying molecular mechanisms. Among several master regulators of EMT, only ZEB1/2 levels were dramatically inhibited by Restin. Unexpectedly, Restin indirectly regulated ZEB1/2 expression at post-transcriptional level. We further identified mir-200a/b, well-characterized mediators controlling ZEB1/2 expression, were transcriptionally activated by Restin and the regulation was dependent on the p53 binding site in mir-200b/a/429 promoter. Further mechanical studies demonstrated Restin interacted with p73, one of p53 family members, which contributed to Restin-mediated activation of mir-200a/b and suppression of ZEB1/2.
\end{abstract}

Conclusions: Taken together, our results suggest that Restin inhibits EMT and tumor metastasis by controlling the expression of the tumor metastasis suppressor mir-200a/b via association with p73. Our findings not only establish a mechanistic link between Restin, EMT and tumor metastasis, but also provide strong evidence supporting the notion that MAGE Group II proteins may exert a tumor suppressive effect in vivo.

Keywords: Restin, EMT, Tumor metastasis, mir-200a/b, p73, Breast cancer, MAGE superfamily

\footnotetext{
*Correspondence: cuishude73@gmail.com; zhenzhenliu73@163.com

${ }^{\dagger}$ Equal contributors

'Department of Breast surgery, Breast Cancer Center, Affiliated Cancer Hospital of Zhengzhou University, Henan Cancer Hospital, \#127 Dongming

Road, Zhengzhou, Henan 450008, People's Republic of China

Full list of author information is available at the end of the article
} 


\section{Background}

The melanoma-associated antigen (MAGE) is one of the well-characterized members of the CTA family that contains at least 60 closely related proteins [1], including MAGE-A, B, C, D, E, F, G, H, L2, Necidin, I and J. According to the protein expression patterns and functions, the MAGE family has been divided into groups I and II $[2,3]$. Group I proteins, including MAGEs A, B and C, are expressed in many types of tumor tissues, but are not expressed in normal tissues [1]. Moreover, their expression is closely correlated with aggressive clinical course, the acquisition of resistance to chemotherapy, the occurrence, and poor clinical outcomes $[1,3,4]$. Contrast to group I proteins, Group II proteins, such as Necdin and Mage-D1, are universally expressed in all normal tissues but rarely in tumor tissues [5]. They are more likely associated with cell growth inhibition, cell cycle arrest, apoptosis, or cell differentiation [6]. For example, Necdin has been shown to be down-regulated in both carcinoma cell lines and primary tumors [7-9], suggesting Necdin is a potent tumor growth suppressor. Ectopic overexpression of Necdin in a mouse tumor cell line is reported to attenuate tumorigenicity and metastasis in vivo [10]. In addition, MAGE-D1 inhibited cell proliferation, migration and invasion of multiple human cancer cells [11]. Although Group II proteins emerge as novel tumor suppressor candidates in a wide range of human cancers, their roles in cancers remain poorly defined.

Restin belongs to MAGE Group II proteins and is known as MAGE H1 [12]. Restin was firstly cloned from the differentiated HL-60 cells induced by all-trans retinoic acid (ATRA) [13], an apoptosis and differentiation inducer. Bioinformatics analysis showed that Restin shared 49\% homology with Necdin [14] and both of them were basic proteins. Further analysis found that Restin, Necdin and Mage-D1 had an alkaline conservative region, which is lowly expressed in tumor tissues [14]. Above data indicated that, similar to Necdin and Mage-D1, Restin belongs to Group II proteins. Bioinformatics data from GEO profiles show that Restin is rarely expressed in a variety of cancer cells, while its expression level is pretty high in normal cells. Restin was identified as one of pro-apoptotic genes that determined the response of multiple tumor cells to CD95-mediated apoptosis [15]. Fu HY et al. found that Restin overexpression in Hela cells promoted apoptosis [16]. Denis Selimovic et al. disclosed that Restin overexpression induced apoptosis of melanoma cells via interacting with p75 neurotrophin receptor (p75NTR), leading to the disruption of both NF-KB and extracellular signal-regulated kinase (ERK) pathways [12]. Thus, Restin may function as a tumor suppressor, which is similar to Necdin and Mage-D1. Nevertheless, little information is available on its expression patterns and functions, particularly its roles in tumorigenesis in vitro and in vivo.
The epithelial-mesenchymal transition (EMT) and the reverse process, termed the mesenchymal-epithelial transition (MET), play critical roles in embryogenesis, wound healing, tissue fibrosis, and carcinoma progression [17-20]. EMT is known to be a central mechanism responsible for invasiveness and metastasis of a variety of cancers [19-21]. During tumor development, epithelial cells undergo dynamic cytoskeletal rearrangement, and lose cell adhesion and epithelial components while acquiring mesenchymal and migratory phenotypes $[20,22]$. Therefore, targeting EMT may serve as an efficient strategy for the treatment of malignant and metastatic tumors.

Our present study, for the first time, demonstrated that Restin remarkably suppressed breast cancer metastasis through inhibiting EMT by controlling the expression and function of the tumor metastasis suppressor mir-200a/b via association with $\mathrm{p} 73$ in breast cancer cells.

\section{Results}

Restin expression level was negatively related with tumor cell mobility

Previous study showed that Restin overexpression induced apoptosis of melanoma cells [12], indicating Restin may be associated with cell malignancy. Thus, we first tested if Restin overexpression inhibited cell proliferation in two breast cancer cell lines. Contrast to melanoma cells, Restin overexpression failed to inhibit cell proliferation determined by ${ }^{3}[\mathrm{H}]$ incorporation assay (Figure 1A). Next, we detected if Restin was related with cell mobility, another tumor cell malignant feature. To test this, Restin expression level was determined in nonmetastatic, low-metastatic and high-metastatic cells. As expected, Restin mRNA level was pretty high in two non-metastatic cells, MCF-10A and HMEC, while it was moderately decreased in low-metastatic MCF-7 cells (Figure 1B). However, Restin was barely detectable in high-metastatic MDA-MB-231 and MDA-MB-451 cells (Figure 1B). Restin protein levels showed the similar trend (Figure $1 C$ ). TGF- $\beta$ is a strong inducer of cell mobility in epithelial cells [23]. As expected, Restin expression level was gradually decreased upon TGF- $\beta$ treatment in MCF-7 cells (Figure 1D). Above data indicated that Restin expression level is negatively related with tumor cell mobility.

\section{Restin prevented EMT in breast cancer cells}

EMT is a crucial program for the invasion and metastasis of epithelial tumors that involves loss of cell-cell adhesion and increase of cell mobility [19-21]. To examine if Restin plays a role in EMT process, cell morphology and EMT markers were detected. Restin overexpression and knockdown stable cell lines were generated in MDA-MB-231 and MCF-7 cells and Restin expression levels were confirmed by western blot (Additional file 1: 

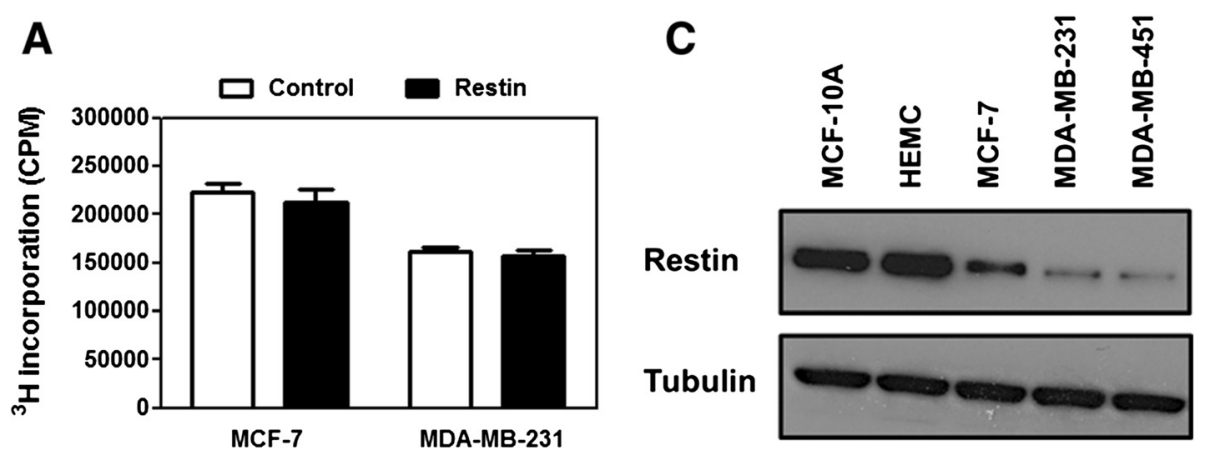

B
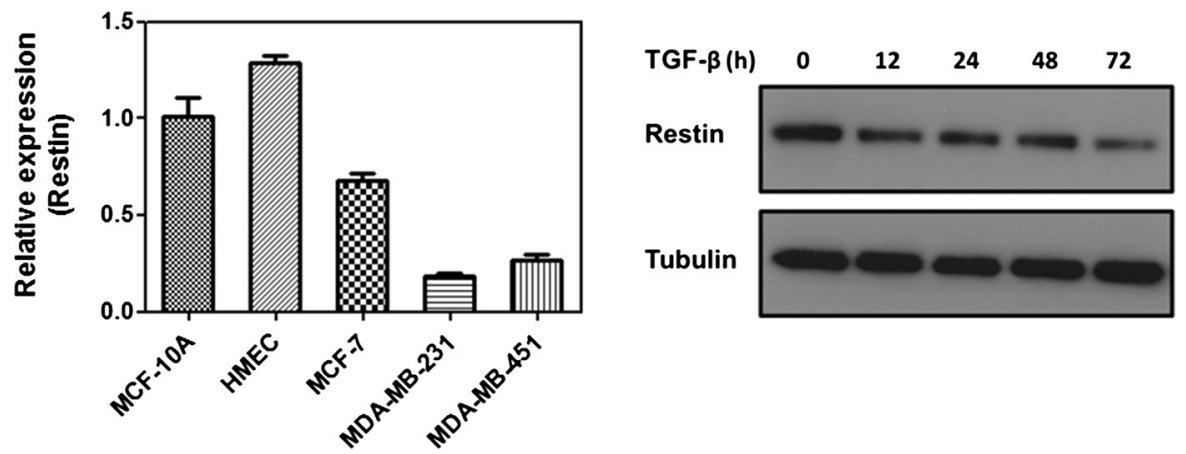

Figure 1 Restin expression level was negatively related with tumor cell mobility. (A) Restin overexpression failed to inhibit cell proliferation determined by $\left[{ }^{3} \mathrm{H}\right]$ thymidine incorporation assay. MCF-7 and MDA-MB-231 $\left(2 \times 10^{4}\right)$ cells were seeded onto $24-w e l l$ plates. $\left[{ }^{3} \mathrm{H}\right]$ thymidine ( $1 \mathrm{mCi} /$ well) was added 4 hours before the termination of experiment. Data were represented as the means \pm S.M. of three independent experiments. mRNA (B) and protein (C) levels of Restin were determined by RT-PCR and western blot. MCF-10A, HMEC, MCF-7, MDA-MB-231 and MDA-MB-451 cells $\left(1 \times 10^{5}\right)$ were seeded onto 6-well plates. Values were expressed as means \pm S.M. of at least three independent experiments. (D) Restin expression in MCF-7 cells upon TGF- $\beta$ treatment was determined by western blot. MCF-7 cells $\left(5 \times 10^{4}\right)$ were seeded onto $6-$ well plates and TGF- $\beta$ $(5 \mathrm{ng} / \mathrm{ml}$ ) were added for 6 days. Tubulin was used as a loading control. Results presented here are representative of three different experiments.

Figure S1). The Control MDA-MB-231 cells retained their elongated spindle-like morphology with sharp borders (Figure 2A). However, Restin overexpressed MDAMB-231 cells displayed a cobblestone-like epithelial phenotype, grew as a monolayer and formed islands of grouped cells with tight cell-cell contact (Figure 2A). In addition to morphological changes, the expression levels of critical genes for EMT process were determined. E-cadherin plays a central role in maintaining epithelial cell-cell adhesion and polarity [24]. Real-time PCR showed a remarkable increase in E-cadherin expression in Restin overexpressed cells (Figure 2B). The concomitant increase in ZO-1 expression was observed either. In contrast, Restin overexpresssion resulted in a strong repression on the expression of mesenchamal markers, including N-cadherin, Vimentin and Fibronectin, in MDA-MB-231 cells (Figure 2B). Similar results were confirmed by western blot analysis (Figure 2C). Thus, morphological alteration from a fibroblastic to an epithelial phenotype and an increase of E-cadherin level upon Restin overexpression strongly indicate that Restin inhibits EMT process. Furthermore, we determined if knockdown of Restin promoted EMT. To this end, cell morphology and EMT markers were tested upon Restin knockdown in low-mobility MCF-7 cells. Although knockdown of Restin failed to change cell morphology (data not shown), these cells apparently exhibited a spindle-like morphology upon TGF- $\beta$ induction (Figure 2D). Consistently, E-cadherin and ZO-1 expression were significantly inhibited, whereas Vimentin and Fibronectin expression were moderately enhanced in Restin knockdown cells as compared to si-Control group (Figure 2E). Our data suggest that Restin inhibits EMT in breast cancer cells.

\section{Restin suppressed migration and invasiveness of breast cancer cells}

Fibroblast cells that have undergone MET are characterized by their decreased motility and loss of invasiveness. Therefore, we detected whether Restin overexpression resulted in decreased motility of MDA-MB-231 and MDA-MB-451 cells determined by wound closure assay, transwell migration and invasion assays. As shown in Figure 3A, the percentage of wound closure for Control MDA-MB-231 cells 
A

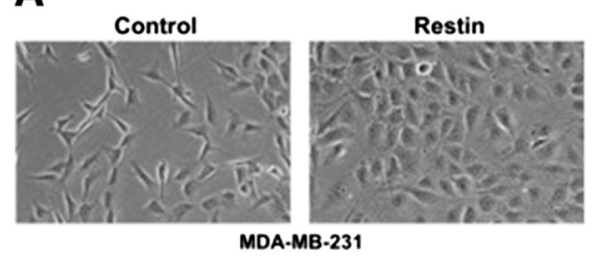

MDA-MB-231
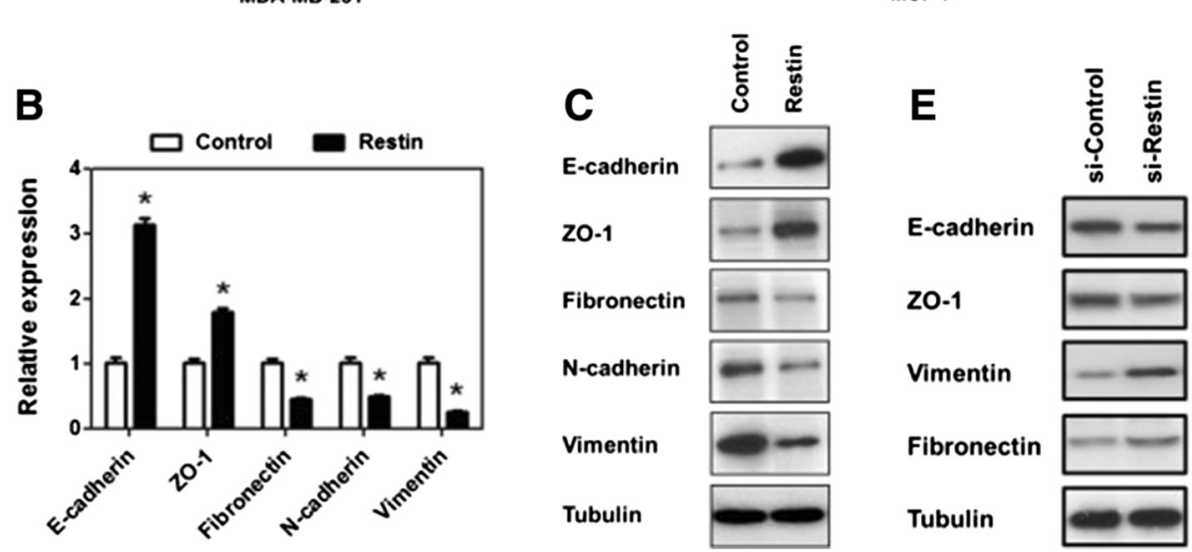

D

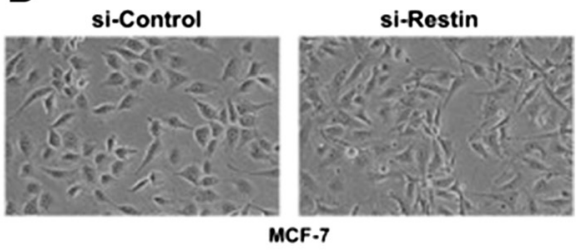

MCF-7

Figure 2 Restin prevented EMT in breast cancer cells. (A) Morphologic changes in MDA-MB-231 cells upon Restin overexpression. Phase-contrast cell images were taken ( $\times 40$ magnification). mRNA (B) and protein levels (C) of epithelial markers (E-cadherin and ZO-1) and mesenchymal markers (Fibronectin, N-cadherin and Vimentin) in MDA-MB-231 cells (Control and Restin overexpression) were determined by real-time PCR and western blot. Values were expressed as means \pm S.M. of at least three independent experiments. ${ }^{*} p<0.05$ vs Control group. Tubulin was used as a loading control. Results presented here were representative of three different experiments. (D) Morphologic changes in MCF-7 cells upon Restin knockdown plus TGF- $\beta$ treatment. MCF-7 cells (si-Control and si-Restin) were seeded onto 6 -well plates and TGF- $\beta$ ( 5 ng/ml) were added for 6 days. Phase-contrast cell images were taken ( $\times 40$ magnification). (E) Protein levels of epithelial markers (E-cadherin and ZO- 1 ) and mesenchymal markers (Fibronectin, N-cadherin and Vimentin) in MCF-7 (si-Control and si-Restin) cells were determined by western blot. Tubulin was used as a loading control. Results presented here were representative of three different experiments. Restin: Restin overexpression; si-Restin: Restin knockdown.

was 50.6\%, whereas Restin-overexpressed cells showed 7.43\% wound closure, suggesting that Restin severely destroys the migration ability of MDA-MB-231 cells. Consistently, Restin overexpression significantly inhibited the number of migrating cells (43.46\% and $40.47 \%$ inhibition in MDA-MB-231 and MDA-MB-451 cells, respectively) compared with Control cells (Figure 3B). Next, we performed transwell matrigel invasion assay to assess whether Restin inhibited cell invasiveness. As shown in Figure 3C, Restin overexpression caused a reduction of invasive cells by more than $41.65 \%$ and $37.61 \%$ in MDA-MB-231 and MDA-MB451 cells compared with their Control cells. We also found that Restin overexpressed cells displayed significantly less adherence to fibronectin compared with Control group (Figure 3D). These results suggest that Restin suppresses cell migration and invasiveness of metastatic breast cancer cells.

\section{Restin inhibited lung metastasis in vivo}

In order to evaluate if Restin-mediated inhibition of EMT indeed plays a role in vivo, tumor growth and lung metastasis were monitored in NOD-SCID mice implanted with Control and Restin overexpressed MDA-MB-231 cells.
The tumor growth rate showed no statistic difference between Control and Restin overexpression groups (Figure 4A, $p>0.05$ ). Consistently, the tumor size was similar in the two groups (Figure $4 \mathrm{~B}$ ). Interestingly, the tumors formed by Control MDA-MB-231 cells gave rise to $13.32 \pm 1.659$ metastatic nodules per lung (Figure $4 \mathrm{C}$ ). However, Restin overexpression resulted in a 2.7-fold decrease of lung metastases (Figures $4 \mathrm{C}$ and D). Our in vivo data indicate that the morphological changes caused by Restin overexpression is closely related to decreased lung metastasis.

\section{Restin downregulated ZEB1/2 expression at post-transcriptional level}

Downregulation of E-cadherin is one of the critical markers of EMT in human breast cancers [25]. FOXC2, Twist, ZEB1, ZEB2, Slug and Snail are identified transcription factors that repress E-cadherin transcription and overexpression of each gene induces EMT and promotes malignant cell invasion and dissemination $[21,24]$. Considering the positive regulation of Restin on E-cadherin, we hypothesize that Restin may control the expression of those transcription factors. We found that the expression 
A
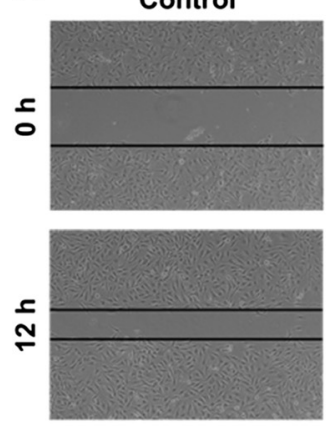

C

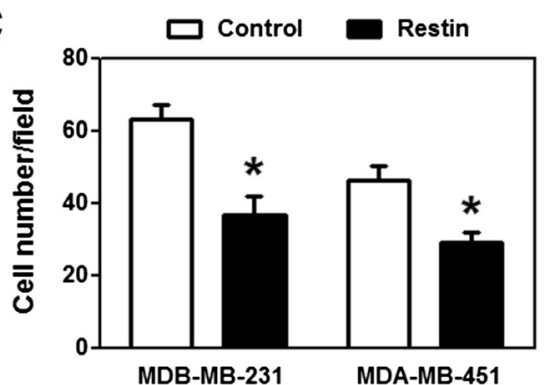

B
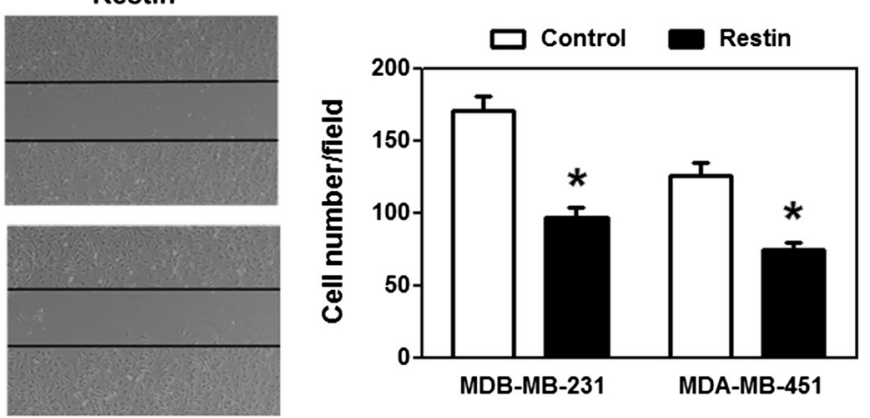

D

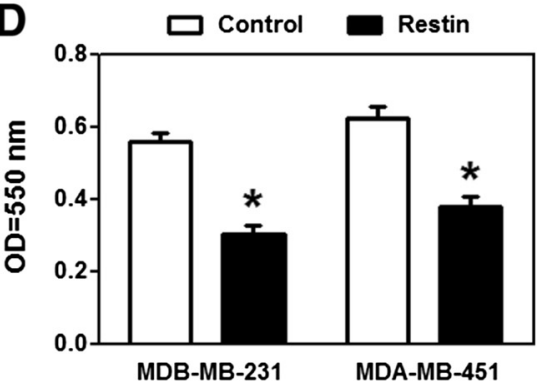

Figure 3 Restin overexpression inhibited migration and invasiveness of breast cancer cells. (A) Scratch wound healing assay of MDA-MB-231 cells. $5 \times 10^{5}$ MDA-MB-231 cells (Control and Restin overexpression) were seeded onto 6-well plates. The 6-well plates were scratched (time 0) and 20 random fields of view per well were photographed after $12 \mathrm{~h}$ of scratch. Representative pictures from 3 independent experiments were shown. The motility of MDA-MB-231 and MDA-MB-451 cells was evaluated by transwell migration (B) and Matrigel invasion assays (C) as described in the Materials and Methods. Migration was quantitated by counting 10 fields at a magnification of $\times 400$. Data were presented as the average number of migrated cells from three independent experiments. ${ }^{*} p<0.05$ vs Control group. (D) Adhesion capacity of MDA-MB-231 and MDA-MB-451 cells was measured by cell attachment assay. MDA-MB-231 and MDA-MB-451 cells (Control and Restin overexpression) were seeded onto 96-well plates pretreated with fibronectin for $30 \mathrm{~min}$ at a density of $2 \times 10^{3}$ cells/well in triplicate. Cells were allowed to adhere for $2 \mathrm{~h}$ and adherent cells were stained with crystal violet and quantified using the absorbance as a measurement at $550 \mathrm{~nm}$. Values were expressed as means \pm S.M. of at least three independent experiments. ${ }^{*} p<0.05$ vs Control.

levels of ZEB1 and ZEB2 were significantly inhibited by $76.4 \%$ and $70.0 \%$, respectively, upon Restin overexpression (Figure 5A). However, a slight reduction in Twist, Snail and Slug mRNA levels was observed (Figure 5A). Consistently, ZEB1 and ZEB2 protein levels were apparently inhibited by Restin overexpression (Figure 5B). However, no apparent difference was observed in Twist and Slug protein levels. On the contrary, Restin knockdown resulted in a dramatic increase in ZEB1 and ZEB2 levels, while only a marginal effect on Twist and Slug expression (Figure 5C, lane 3 versus lane 1 ). Consistent with TGF- $\beta$ mediated negative regulation on Restin, TGF- $\beta$ treatment further enhanced ZEB1 and ZEB2 expression levels (Figure $5 \mathrm{C}$, lane 4 versus lane 2).

Next, we determined if ZEB1/2 was involved in Restin-mediated inhibition of EMT. E-cadherin, Vimentin and Fibronectin levels were tested upon ZEB1 knockdown (Additional file 1: Figure S2). Control MCF-7 cells transfected with ZEB1 siRNAs showed moderately enhanced E-cadherin and decreased Vimentin and Fibronectin expression (Figure 5D, lane 2 relative to lane 1), which is consistent with ZEB1 function in promoting EMT.
Restin knockdown led to reduction of E-cadherin and increase of Vimentin and Fibronectin (Figure 5D, lane 3 relative to lane 1). Additional knockdown of ZEB1 effectively reversed the expression of these proteins, and their levels were comparable to that in Control cells (Figure 5D, lane 4 relative to lane 2). Collectively, these data indicate that ZEB1 is a crucial mediator of Restininduced phenotypes.

Previous studies showed that Restin was localized in nucleus and it interacted with several transcription factors [26,27], indicating it may regulate ZEB1 expression at the transcriptional level. To test this, ZEB1 promoter activity was detected by luciferase reporter assay. We found that Restin overexpression failed to activate the transcription of ZEB1 (Figure 5E). Since Restin suppressed ZEB1 and ZEB2 mRNA levels, it is possible that Restin may regulate ZEB1 expression at the posttranscriptional level. As expected, Restin overexpression strongly repressed the luciferase activities driven by ZEB1 3'UTR in a dose-dependent manner (Figure 5F). Furthermore, an enhanced luciferase activity was observed upon Restin knockdown (Additional file 1: Figure S3). 


\section{mir-200a/b was responsible for Restin-mediated downregulation of ZEB1}

Accumulating evidences demonstrate that mir-200 family is a powerful microRNA family controlling ZEB1/2 expression $[23,28]$. To determine if mir-200 members are involved in Restin-mediated downregulation of ZEB1/2, mir-200a, mir-200b, mir-429, mir-200c and mir-141 levels were determined upon Restin overexpression and knockdown. As shown in Figure 6A, overexpression of Restin significantly enhanced mir-200a and mir-200b expression by 2.71 - and 2.07 -fold, while their levels were greatly inhibited by Restin knockdown (Figure 6B), hinting that Restin may regulate the transcription of mir-200b/a/429. However, the expression levels of mir-200c and mir-141, which are located in another genomic cluster, were not altered by Restin overexpression (Additional file 1: Figure S4). Our hypothesis was further confirmed by luciferase reporter assay showing that Restin significantly increased the luciferase activity driven by mir200b/a/429 promoter but not mir-200c/141 promoter (Figure 6C and Additional file 1: Figure S5). Next we determined if $\mathrm{mir}-200 \mathrm{~b} / \mathrm{a}$ is indeed responsible for Restin-mediated downregulation of ZEB1 and ZEB2. To this end, a mutant ZEB1 3'UTR with deletion of mir$200 \mathrm{~b}$ binding sites was constructed. Consistent with above data, Restin overexpression decreased the luciferase activities driven by ZEB1 3'UTR, while failed to reduce the luciferase activities driven by mutant ZEB1 3'UTR (Figure 6D).

\section{Restin activated mir-200b/a/429 transcription in a p73-dependent manner}

To investigate the molecular mechanisms by which Restin upregulated mir-200b/a transcription, a series of mir-200b/ a/429 promoter truncations were constructed (Figure 7A) and their luciferase activities were determined. As shown in Figure 7B, Restin dramatically enhanced the luciferase activities driven by WT mir-200b/a/429 promoter (P1,$1574 /+120)$. However, Restin failed to activate the mir$200 \mathrm{~b} / \mathrm{a} / 429$ promoter activities with deletion of p53 binding sites $(-1412 /-1408)$ in P2 truncation $(-1000 /+120)$ and another two shorter truncations (P3 and P4). Above data suggest that p53 binding site is critical for Restin-mediated activation of mir-200b/a/429 transcription. To further demonstrate this, we introduced a luciferase reporter construct in which the p53 binding site had been mutated (Figure 7C, bottom panel). As expected, the luciferase activities driven by WT mir-200b/a/429 promoter was increased by 1.69 fold upon Restin overexpression, whereas Restin was unable to upregulate the activities of mir-200b/a/429 promoter with mutations in p53 binding site (Figure 7C). These data indicate that Restin directly or indirectly activates the transcription of mir-200b/a/429 through p53 binding site on its promoter.
The p53 family comprises three genes that encode for p53, p63 and p73 [29]. To identify which factor is involved in Restin-activated mir-200b/a/429 transcription, the expression levels of three proteins were first detected in several breast cancer cell lines. It is well-documented that MCF-7 cells contain wild-type p53, MDA-MB-231 cells carry mutant p53 with greater levels, and MDA-MB-157 cells expressed no p53 [30]. As shown in Figure 7D, p53 was moderately expressed in MCF-7 cells, and was undetectable in MDA-MB-157 cells, whereas a high level of mutant p53 protein was observed in MDA-MB-231 cells. All cell lines were negative for p63 (data not shown), whereas contained detectable and comparable p73 levels (Figure 7D). It has been demonstrated that MDA-MB-231 cells have mutant p53 due to an arginine to lysine mutation at position 280 and the mutant p53 does not retain the tumor suppressive ability of wild-type p53 [30]. We compared the luciferase activities driven by mir-200b/a/429 promoter in above three cell lines and found that Restin activated the luciferase activities in a comparable manner whatever the expression level and function of p53 in those cells (Additional file 1: Figure S6). Therefore, we postulate that p53 may not participate in Restin-mediated transcriptional activation of mir-200b/a/429. Considering the undetectable level of p63, we hypothesize that p73 may play a role in Restin-mediated upregulation of mir-200b/a. To test this, reciprocal co-immunoprecipitation was performed to detect the interaction between p73 and Restin. HERK-293 cells were transiently transfected with Flag-tagged Restin and His-tagged p73 plasmids. Upon immunoprecipitation of p73 using an anti-His antibody, Restin was coimmunoprecipitated (Figure 7E, upper panel). Likewise, in the immunoprecipitate of Flag-Restin, p73 protein was recovered (Figure 7E, lower panel). Endogenous interaction of p73 and Restin was also examined in MCF-7 cells. AntiRestin antibody could co-immunoprecipitate endogenous p73 (Additional file 1: Figure S7). As expected, endogenous interaction between p53 and Restin was not found in MCF-7 cells determined by co-immunoprecipitation assay (Additional file 1: Figure S8).

Next we investigated if Restin upregulated mir-200b/a transcription in a p73-dependent manner. siRNAs mediated p73 knockdown was confirmed by western blot (Additional file 1: Figure S9). In MDA-MB-231 Control cells, knockdown of p73 inhibited the luciferase activities driven by mir-200b/a/429 promoter by 0.69 -fold, suggesting that $\mathrm{p} 73$ indeed regulates the transcription of mir-200b/a/429 (Figure 7F, lane 2 relative to lane 1). In Restin overexpressed cells, the luciferase activity was dramatically increased by 3.20 -fold compared to Control cells (Figure 7F, lane 3 relative to lane 1). However, its activity was significantly decreased by 2.93 -fold upon p73 knockdown (Figure 7F, lane 4 relative to lane 3 ) and reached to the level exhibited by Control cells plus p73 

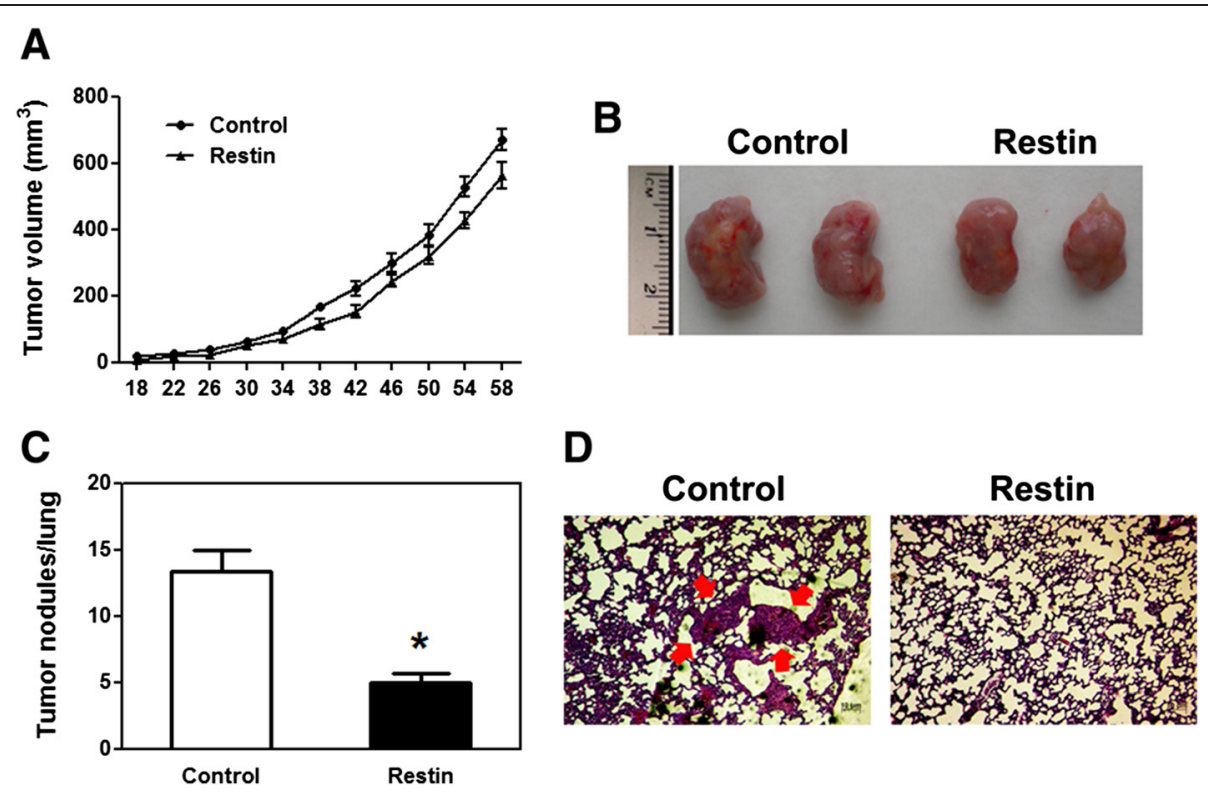

Figure 4 Restin overexpression inhibited lung metastasis in vivo. (A) The volume of primary tumors was measured after the transplantation of Control and Restin overexpressed MDA-MB-231 cells. $1 \times 10^{5}$ MDA-MB-231 cells were subcutaneously injected into the mammary fat pad of immunocompromised NOD/SCID mice $(n=5)$. Tumor growth was monitored every 4 days. Data were shown as mean size $\pm S . M$. of tumors in five mice per cell line. Animal experiments were repeated three times. (B) Xenograft tumor size from NOD/SCID mice grafted with Control and Restin-overexpressed cells. (C) The metastatic nodules in the lungs were counted following the orthotopic transplantation of Control and Restin overexpressed MDA-MB-231 cells. Values were expressed as means \pm S.M. in five mice. ${ }^{*} p<0.05$ vs Control. (D) Representative HE staining of lung metastases. Arrows indicate micrometastases.

knockdown (Figure 7F, lane 4 relative to lane 2). Consistently, we found that p73 knockdown slightly decreased mir-200a/b expression level which was apparently enhanced by Restin overexpression (Figure 7G). However, p73 knockdown remarkably diminished mir-200a/b expression to the similar level as seen in the MDA-MB-231 Control cells (Figure 7G). To further confirm the contribution of p73 to Restin-mediated regulation of mir-200b/a, levels of ZEB1/2, targets of mir-200b/a, were evaluated upon p73 knockdown. Although Restin overexpression apparently inhibited ZEB1/2 expression (Figure $7 \mathrm{H}$, lane 3 relative to lane 1), p73 knockdown almost restored ZEB1/2 expression to the levels observed in Control cells (Figure $7 \mathrm{H}$, lane 4 relative to lane 2), suggesting that p73 is a critical mediator for Restin-induced upregualtion of mir-200b/a and downregulation of ZEB1/2.

\section{Discussion}

MAGE group II proteins function as putative tumor suppressors in a variety of cancers $[5,6]$. However, its clinical effects on tumor development and the underlying mechanisms are poorly characterized. Restin is a novel member of MAGE group II proteins [12]. Selimovic et al. demonstrated Restin induced apoptosis of melanoma cells via interaction with p75 neurotrophin receptor [12]. Wang et al. showed that p53 upregulated Restin expression at the transcriptional level [31]. All current data hint that
Restin may be involved in tumor cell growth. Nevertheless, the molecular mechanisms underlying the repression of Restin in tumor cells and its role in tumor development had not been reported yet. Here, we, for the first time, showed that Restin suppressed EMT and lung metastasis by activating the transcription of mir$200 \mathrm{~b} / \mathrm{a}$ via association with p73. Considering the pivotal roles of mir-200b/a and p73 in tumorigenesis, our studies provide significant insights that Restin may participate in other functions closely related to mir-200b/a and p73, such as EMT, cancer stem cells, tumor angiogenesis and drug resistance.

mir-200 family plays critical roles in tumor development and progression through inhibiting EMT and suppressing tumor invasion by directly repressing the transcription factors ZEB1 and ZEB2 [23,28,32,33]. Previous works on mir-200 regulation have largely focused on mechanisms of transcriptional inhibition, epigenetic modification and transcriptional activation of this miRNA family, and identified multiple factors regulating mir-200 expression, including ZEB1, ZEB2, HDAC, p53 family [32]. Our study demonstrated that Restin upregulated mir-200 expression at the transcriptional level, indicating Restin may serve as a novel regulator of mir200. However, Restin-mediated upregulation of mir200b/a/429 was dependent on p53 binding site in its promoter, indicating p53 family members (p53, p63, 
A

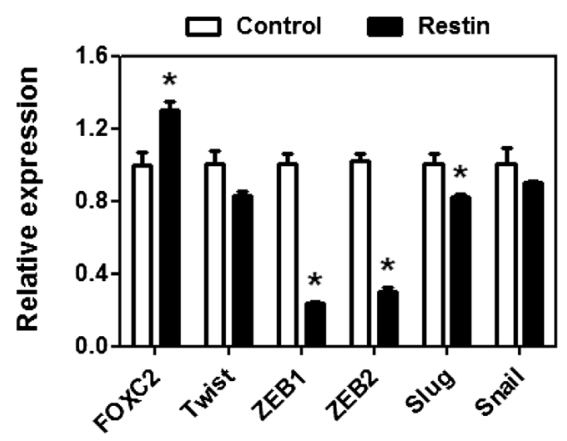

C

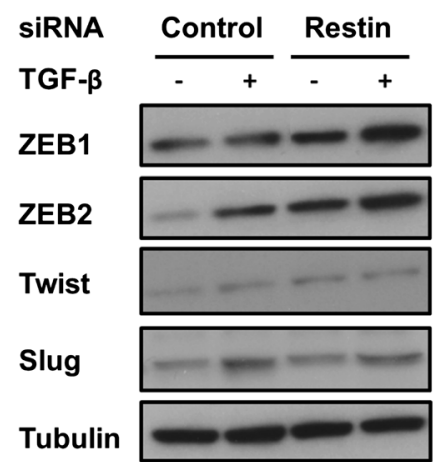

E

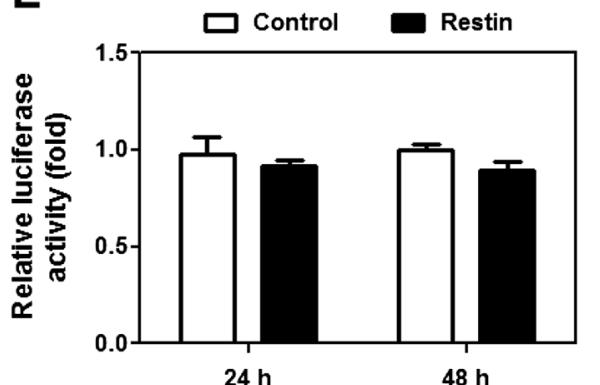

B

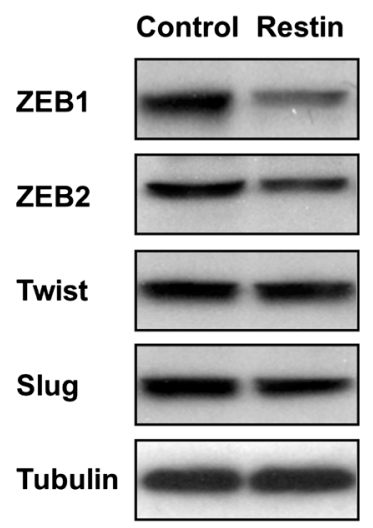

D

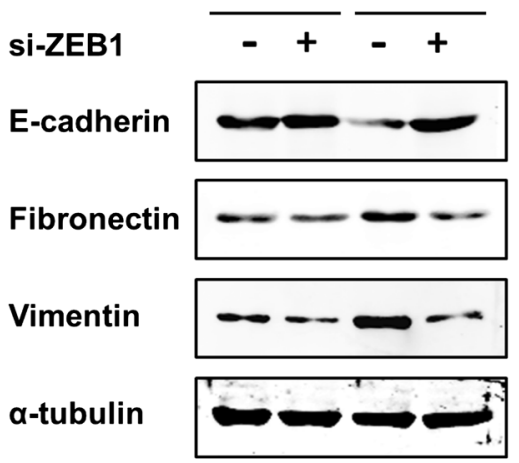

$\mathbf{F}$

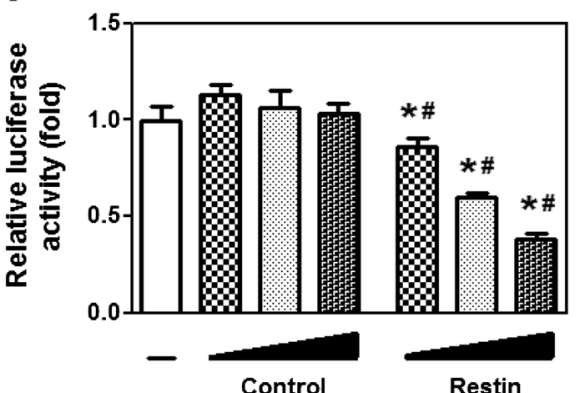

Figure 5 Restin downregulated ZEB1/2 expression at the post-transcriptional level. RNA (A) and protein levels (B) of FOXC2, Twist, ZEB1, ZEB2, Slug and Snail in Control and Restin overexpressed MDA-MB-231 cells were determined by real-time PCR and western blot. Values were expressed as means \pm S.M. of at least three independent experiments. ${ }^{*} p<0.05$ vs Control group. (C) Expression level of above proteins in si-Control and si-Restin MCF-7 cells treated with TGF- $\beta$ was determined by western blot. Tubulin was used as a loading control. Results presented here were representative of three different experiments. (D) MCF-7 stable cells (si-Control and si-Restin) were seed onto 6-well plates and transfected with control and ZEB1 siRNAs (si-ZEB1). $48 \mathrm{~h}$ posttransfection, proteins were collected and western blot was performed to detect protein levels of E-cadherin, Fibronectin and Vimentin. Tubulin was used as a loading control. Result presented here was a representative of three different experiments. (E) ZEB1 promoter activity was determined by luciferase reporter assay. HEK293 cells were seeded in 24-well plates and transfected with Restin overexpression lentivirus and ZEB1 promoter plasmids. The firefly luciferase activity was normalized to that of the renilla luciferase. (F) ZEB1 3'UTR activity was determined in HEK293 cells by luciferase reporter assay upon Restin overexpression. HEK293 cells were seeded in 24-well plates and transfected with ZEB1 3'UTR plasmids and different dose of Restin overexpression lentivirus. The firefly luciferase activity was normalized to that of the renilla luciferase. Values were expressed as means \pm S.M. of at least three independent experiments. ${ }^{*} p<0.05$ relative to cells without addition of lentivirus (-), ${ }^{\#} p<0.05$ relative to Control group.

p73) are involved in above process. p53 suppresses EMT by transactivating the expression of mir-200 family members in primary hepatocellular carcinomas (HCCs) and 9 HCC cell lines [34]. Simlar to p53, p73 and p63 can directly associate with the mir-200b/a/429 promoter and activate mir-200 transcription in ovarian carcinoma cells [35]. Although MDA-MB-231 cells or MDA-MB157 cells possess mutant p53 or no p53 expression, 
A

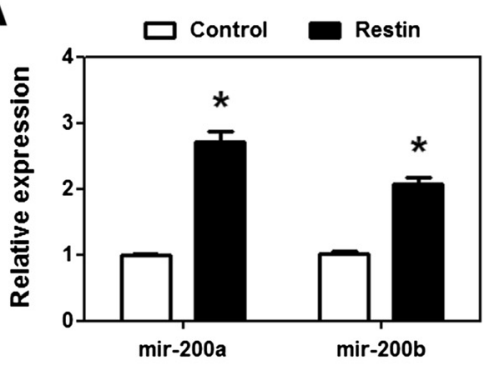

C

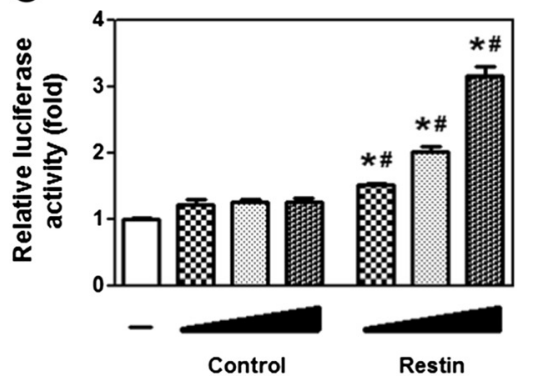

B

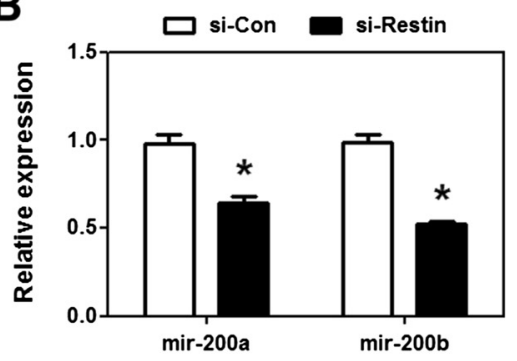

D

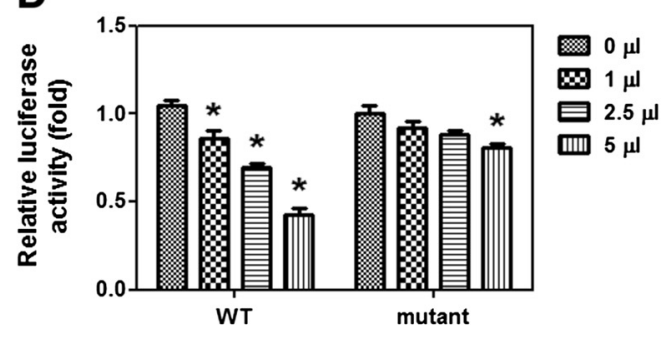

Figure 6 mir-200b/a was responsible for Restin-mediated downregulation of ZEB1. RT-PCR was performed to detect mir-200a and mir-200b levels in Restin overexpressed MDA-MB-231 cells (A) and Restin knockdown MCF-7 cells (B). Values were expressed as means \pm S.M. of at least three independent experiments. ${ }^{*} p<0.05$ relative to Control or si-Con group. (C) mir-200b/a/429 promoter activity was determined in HEK293 cells by luciferase reporter assay. HEK293 cells were seeded ontn 24-well plates and transfected with mir-200b/a/429 promoter plasmids and different dose of Restin overexpression lentivirus. The firefly luciferase activity was normalized to that of the renilla luciferase. Values were expressed as means \pm S.M. of at least three independent experiments. ${ }^{*} p<0.05$ relative to cells without addition of lentivirus $(-)$, ${ }^{\#} p<0.05$ relative to their Control group. (D) ZEB1 3'UTR (WT and mutant) activity was determined by luciferase reporter assay upon Restin overexpression. WT and mutant ZEB1 3'UTR with deletion of mir-200 binding sites were transfected into HEK293 cells. 24 h later, different dose of Restin overexpression lentivirus were added. The firefly luciferase activity was normalized to that of the renilla luciferase. Values were expressed as means \pm S.M. of at least three independent experiments. ${ }^{*} p<0.05$ relative to cells without addition of Restin lentivirus.

Restin still activated mir-200b/a/429 transcription, indicating p53 protein may not participate in above process and Restin may not associate with p53. Our hypothesis was proven by our data showing that no endogenous interaction between Restin and p53 was found. By performing Co-IP experiment, we found that Restin can closely interact with p73. Moreover, p73 knockdown diminished Restin-mediated regulation on mir-200a/b and ZEB1/2. Thus, our observations provide new insights into the role of p53 family members in mediating Restin's function in tumorigenicity.

Based on the chromosomal locations, the mir-200 family can be divided into two clusters: the mir-200b/a/ 429 cluster containing mir-200a, mir-200b and mir-429, and the mir-200c/141 cluster, which contains mir-200c and mir-141 [32]. Although both clusters contained putative p53 binding sites, Restin drove mir-200b/a/429 transcription rather than that of mir-200c/141 via association with p73. Interestingly, a recent report found that in mammary epithelial cells, p53 serves as a transcriptional activator of mir-200c/141, but not of the mir$200 \mathrm{~b} / \mathrm{a} / 429$ [36]. We speculate that the transcription of mir-200 clusters by p53 family members may be dependent on the expression level and functions of p53 family members, the promoter methylation status of mir-200 promoters or other transcriptional co-factors, which need to be further elucidated.

p53 is involved in tumor initiation as well as tumor progression [37-39]. However, deletions or mutations of p53 are frequently found in cancers [39-43]. p63 and p73 are rarely mutated in a large number of tumors examined to date [42]. Therefore, in the absence of p53, these proteins may be involved in the control of the ZEB/mir-200 equilibrium and EMT-MET plasticity. Our data showed that Restin interacted with p73 rather than p53 and upregulated mir-200b/a expression even in p53 mutant cells. Our results shed light on the transcriptional regulation of Restin on mir-200s, which has potential therapeutic value in the development of approaches aimed at modifying mir-200s expression for the treatment of diverse forms of human cancers, especially those cancers with p53 mutation.

Restin was identified from HL-60 cells induced by alltrans-retinoic acid (ATRA). Restin expression level was undetectable in HL-60 cells, whereas its level was sharply increased upon ATRA treatment $[13,14]$. Consistently, we observed that Restin expression was pretty high in normal breast epithelial cells compared to breast cancer cells. Its 

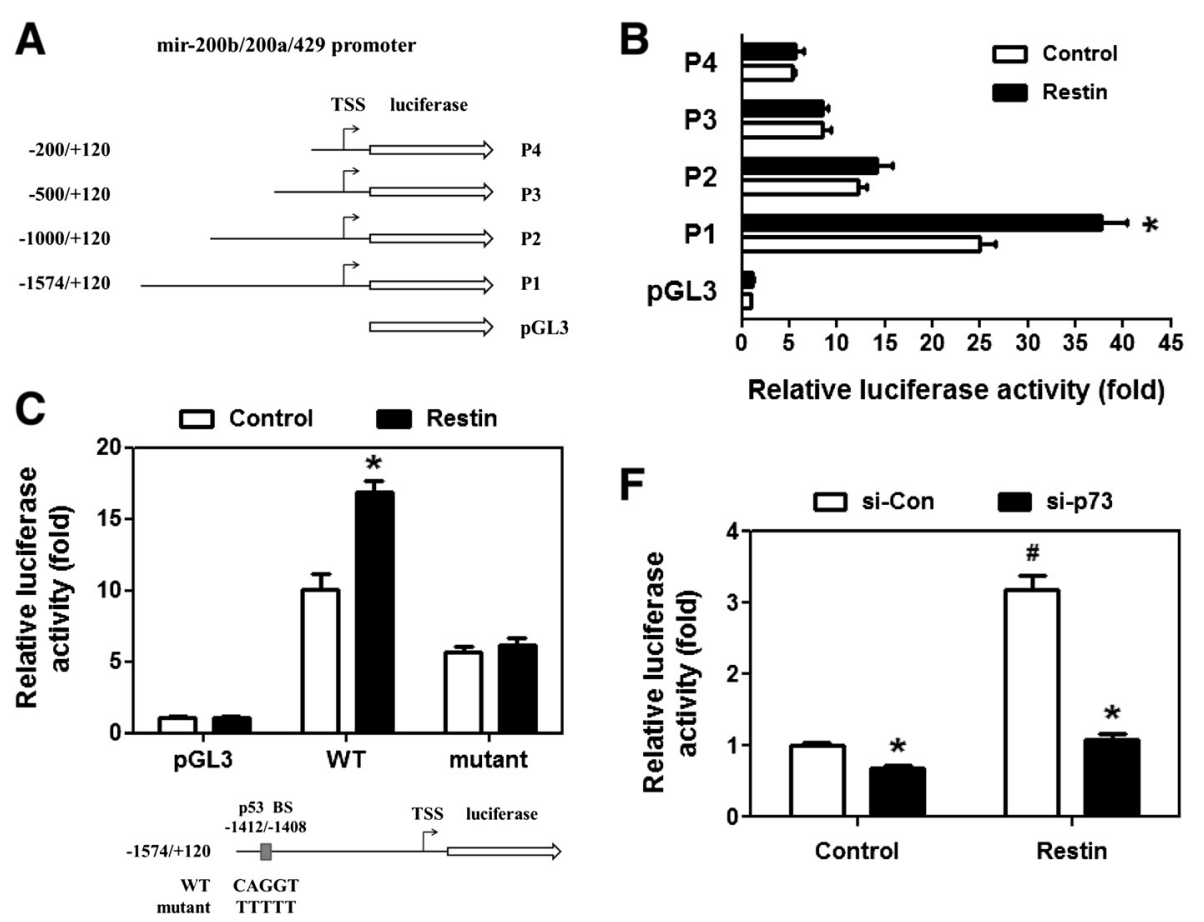

D
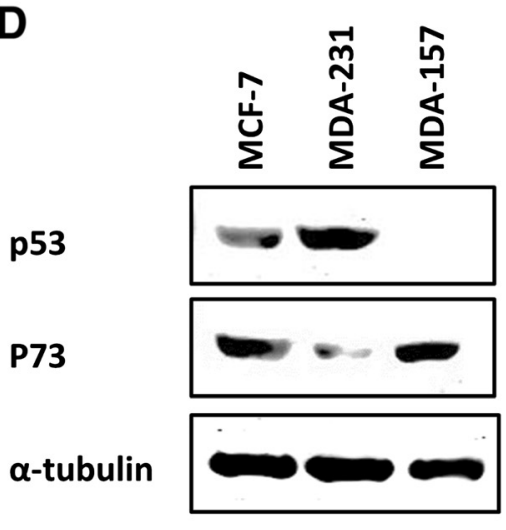

E

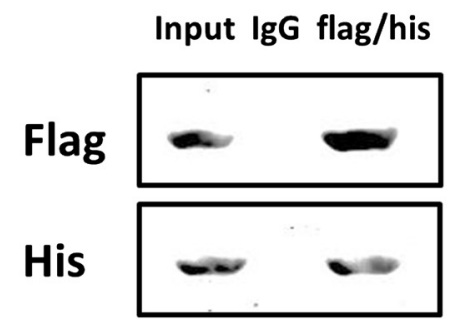

G

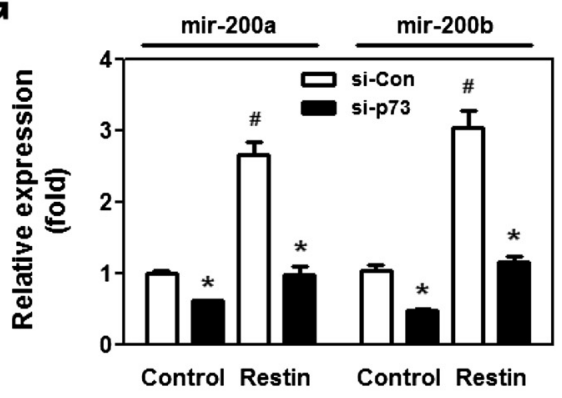

H

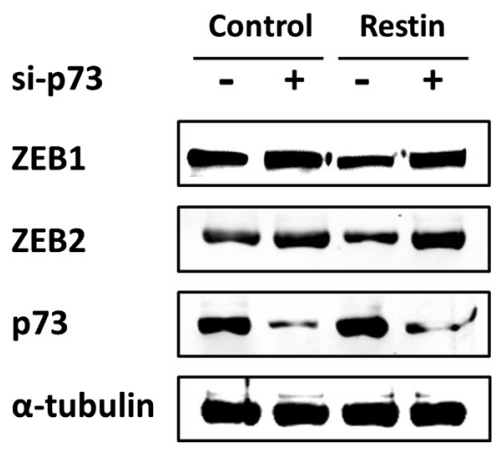


(See figure on previous page.)

Figure 7 Restin activated mir-200 transcription in a p73-dependent manner. (A) A schematic diagram of the human mir-200b/a/429luciferase constructs (WT and its truncations) was shown. (B) A series of mir-200b/a/429 promoter activities were determined by luciferase reporter assay. Restin overexpression lentivirus were added into 293T cells and mir-200b/a/429 promoter truncation plasmids were transiently transfected. * $p<0.05$ relative to Control lentivirus. (C) mir-200b/a/429 promoter (WT and p53 mutant) activities were measured by luciferase reporter assay. ${ }^{*} p<0.05$ relative to Control lentivirus. (D) Western blot was performed to detect p53 and p73 levels in MCF-7, MDA-MB-231 and MDA-MB-157 cells. (E) Co-immunoprecipitation assay was performed to detect the exogenous interaction between Restin and p73. HERK-293 cells were transiently transfected with Flag-tagged Restin and His-tagged p73 plasmids. (Upper panel) Cell extracts were immunoprecipitated with mouse lgG or anti-His antibody and then blotted with anti-Flag antibodies. (Lower panel) Cell extracts were immunoprecipitated with mouse IgG or anti-Flag antibody and then blotted with anti-His antibody. (F) MDA-MB-231 stable cells (Control and Restin overexpression) were seed onto 24-well plates and co-transfected with Control or p73 siRNAs (si-Con and si-p73) and mir-200b/a/429 promoter construct. ${ }^{*} p<0.05$ relative to si-Con group, \# $p<0.05$ relative to Control cells. (G) MDA-MB-231 stable cells (Control and Restin overexpression) were seed onto 6-well plates and transfected with control and p73 siRNAs (si-Con and si-p73). RT-PCR was performed to detect mir-200a and mir-200b expression levels. ${ }^{*} p<0.05$ relative to si-Con group, \# $p<0.05$ relative to Control cells. (H) MDA-MB-231 stable cells (Control and Restin overexpression) were seed onto 6-well plates and transfected with control and p73 siRNAs (si-p73). Western blot was performed to detect ZEB1 and ZEB2 levels.

expression in low-metastatic cells was higher than that in high-metastatic cells, hinting that Restin expression level is negatively related to tumor cell malignancy. Our data was supported by current evidence showing that Necdin, another member of MAGE group II proteins, was expressed at a low level in MDA-MB-468 and MDA-MB-231 cells, but exhibited much higher levle in low-metastatic MCF-7 cells [8]. Contrast to Restin and Necdin, MAGE-A and C, belong to MAGE group I proteins, exerted an oncogenic role in breast cancer and exhibited a positive correlation with tumor malignancy $[1,3,4]$. Considering the undetectable expression of Restin in high-metastatic MDA-MB-231 cells and the dramatic inhibition of tumor metastasis by Restin overexpression, we hypothesize that Restin may function as a tumor-suppressor in breast cancers. Our ongoing studies are being performed to detect Restin expression in normal breast tissues, para-carcinoma tissues and carcinoma tissues and to statistically analyze the association of its expression level with tumor malignant grade, tumor metastasis, relapse, and clinical prognosis, which will strongly support our hypothesis.

\section{Conclusions}

Taken together, our study, for the first time, demonstrated that Restin strongly inhibited lung metastasis in vivo, which strongly suggests that Restin may serve as a potent tumor suppressor in breast cancers although our study is still in a preliminary stage. Our current data not only shed a light on the function of Restin in tumor development in light of its inhibition on EMT process but also facilitate other researchers to extend or verify its function in other type of cancers.

\section{Materials and methods}

\section{Cell culture and reagents}

MCF-7, MDA-MB-157, MDA-MB-231 and MDA-MB451 breast cancer cells were grown in Dulbecco's modified Eagle's medium (Gibco, Grand Island, NY) supplemented with $10 \%$ fetal bovine serum, $2 \mathrm{mM}$ glutamine, $100 \mathrm{U} / \mathrm{ml}$ penicillin, and $100 \mu \mathrm{g} / \mathrm{ml}$ streptomycin at $37^{\circ} \mathrm{C}$ in a humidified atmosphere of 5\% CO2. MCF-10A, a spontaneously immortalized human breast epithelial cell line, was maintained in DMEM/F12 medium (Invitrogen Life Technologies, Carlsbad, CA). Human mammary epithelial cells (HMEC) were cultured in mammary epithelial cell complete medium (Invitrogen). All cell lines were obtained from the ATCC. p73 and ZEB1 siRNAs (Stealth $^{\text {тм }}$ siRNAs) were synthesized from Invitrogen and were dissolved in DEPC-treated $\mathrm{H}_{2} \mathrm{O}$ at a concentration of $20 \mathrm{pmol} / \mu \mathrm{l}$ as a stock.

\section{Generation of Restin overexpression and knockdown stable cell lines}

Restin coding region was amplified by PCR using MCF-7 cDNA as a template and inserted into PmeI restriction enzyme sites of pWPI-GFP lentivirus expression vector by using the following primers: 5'-gtacgtttaaacatgcctcgggag cgaaagag-3' and 5'-gatcgtttaaacttaaggggcggaataacccc-3'. siRNA duplexes targeting Restin were annealed and inserted into Mlu1 and Cla1 restriction enzyme sites of pLVTHM-GFP lentivirus expression vector. Forward: 5'-cgcgtccc ggaatcgagcaaactgaaattcaagagattcagtttgctcg attcctttttggaaat-3'; Reverse: 5'-cgatttccaaaaaggaatcgagc aaactgaaatctcttgaattcagtttgctcgattccgggga-3'. The PCR products were confirmed by sequencing. Lentivirus were produced according to the manufacture's instruction. MCF-7 and MDA-MB-231 cells were seeded onn 6-well plates and transduced with $10 \mu$ lentivirus. $24 \mathrm{~h}$ later, transfected cells were trypsinized and reseeded into $10-\mathrm{cm}$ culture plates. We refer to these cells in the text as Control and Restin (overexpression), si-Control and si-Restin (knockdown).

\section{Constructs}

The following plasmids were bought from Addgene (Cambridge, MA). mir-200b-200a-429 promoter (Plasmid 35539: pGL3-1574/+120), mir-200c-141 (Plasmid 35534), 
ZEB1 3'UTR (Plasmid 35535: pCI-neo-RL-ZEB1), ZEB1 3'UTR with mutation in mir-200b seeding region (Plasmid 35537: pCI-neo-RL-ZEB1 200bmutx5). ZEB1 promoter plasmid (HPRM23421) was bought from GeneCopoeia (Rockville, MD). 2000 bp of mir-200c-141 promoter region was amplified and inserted into pGL3 vector using Nhe I and Bgl II sites. A series of mir-200 promoter truncations were amplified by using mir-200 promoter plasmid (pGL3-1574/+120) as a template and cloned into the pGL3-basic (Promega) reporter using Nhe I and $\mathrm{Bgl}$ II sites. The primer sequences were as follows: pGL3-1000/+120: forward, 5'-gtgctagcGAAAACCGTGGG GTCCGCTG-3'; pGL3-200/+120: forward, 5'-acgctagc AAGGTGGGGGCGGGACGGAG-3'; reverse, 5'-ctagatct CCTGGCACAGGAAGTCAGTTC-3'. Mutation in the p53 binding site was made by using the Quikchange Multi site-directed mutagenesis kit (Stratagene, La Jolla, CA) using the primer pairs 5'-CCAGCTCCCAGGTTTTTCC CGCCG -3 ' and 5'-CGGCGGGAAAAACCTGGGAGC TGG-3' (p53 mutant) (the mutation sites were shown in bold) . Restin and p73 coding regions were amplified using MCF-7 cDNA as a template and inserted into our previously recombined pcDNA3.1 (+)-flag and pcDNA3.1 (+)-his vectors, respectively.

\section{In vivo animal experiments}

NOD/SCID mice were purchased from Beijing HFK Bioscience CO., LTD (Bejing, China). All animal experiments were performed under the approval of Institutional Animal Care and Use Committee (IACUC) at Henan Cancer Hospital (Permit No: 2014ct001). $1 \times 10^{6}$ MDA-MB-231 cells were resuspended in $20 \mu \mathrm{l}$ PBS and subcutaneously injected into the fourth mammary fat pad of 8-week old female NOD/SCID mice ( $\mathrm{n}=5$ mice/group). Primary tumor growth was evaluated every four days by caliper, and tumor volume was estimated using the following formula: $\left(L \times W^{2}\right) / 2$. Metastatic growth in the lung was allowed to develop for 6-8 weeks. Primary tumors and lung tissues were fixed in $10 \%$ neutral buffered formalin, embedded in paraffin, and subjected to standard hematoxylin and eosin ( $\mathrm{H}$ \& $\mathrm{E})$ staining.

\section{Transfection and luciferase reporter assay}

Cells were seeded onto 24-well plates and transfected with $800 \mathrm{ng}$ of luciferase vectors (ZEB promoter, mir-200 promoter, ZEB 3'UTR (WT and mutant)) per well using Lipofectamine $^{2000}$ Transfection Reagent (Invitrogen). 50 ng of pBind plasmids were cotransfected to normalize for transfection efficiency. $24 \mathrm{~h}$ later, cells were lysed with PLB lysing buffer. The luciferase activities were measured with the dual-luciferase reagent assay kit (Promega, Madison, WI) according to the manufacturer's instructions using the TD-20/20 Luminometer (Turner Designs).
All reporter assays are shown as relative luciferase activities (averaged ratios of Firefly luciferase: Renilla FSE) and are representative of three experiments.

\section{Quantitative real-time PCR}

RNAs were collected using Trizol Reagent (Invitrogen). Reverse transcription was carried out using $2 \mu \mathrm{g}$ RNA in a $20 \mu \mathrm{l}$ reaction volume using the Superscript III Reverse Transcription Kit (Invitrogen). Real-time PCR was performed with the SYBR ${ }^{\circ}$ Premix Ex Taq ${ }^{\mathrm{TM}}$ (Takara Biotechnology, Dalian, China) in $20 \mu \mathrm{l}$ reactions using ABI PRISM - 7500 Real-Time PCR System (Applied Biosystems, Grand Island, NY). GAPDH was used as an internal control. Primer sequences are listed in the Additional file 1: Table S1. For mir-200 detection, RNAs were reverse transcribed by miScript Reverse Transcription Kit (Qiagen, Valencia, CA). qPCR of mir-200a and 200b was performed using miScript SYBR Green PCR Kits (Qiagen). mir-200 expression was normalized with U6.

\section{Western blot}

MDA-MB-231 cells were harvested and lysed in a RIPA buffer containing $50 \mathrm{mM}$ Tris- $\mathrm{HCl}, \mathrm{pH} 7.5,150 \mathrm{mM}$ $\mathrm{NaCl}, 1 \% \mathrm{NP}-40,0.1 \% \mathrm{SDS}, 0.5 \%$ sodium deoxycholate, and $50 \mathrm{mM} \mathrm{NaF}$. One tablet of protease inhibitor mixture (Complete Mini, Roche Applied Science) was added just prior to use. Then $30 \mu \mathrm{g}$ protein lysates were separated by 12\% SDS-PAGE and transferred onto nitrocellulose. After blocking in a $5 \%$ non-fat dried milk solution in washing buffer containing $10 \mathrm{mmol} / \mathrm{l}$ Tris (pH 7.5), $50 \mathrm{mmol} / \mathrm{l}$ $\mathrm{NaCl}$, and $0.02 \%$ Tween 20 (TBST), membranes were incubated overnight at $4^{\circ} \mathrm{C}$ with primary antibodies. After washed three times with TBST, membranes were incubated for $1 \mathrm{~h}$ with horseradish peroxidase-coupled secondary antibodies at room temperature. Signals were detected with the ECL kit (Pierce, Rockford, IL).

\section{Antibodies}

The following antibodies were used: rabbit polyclonal anti-Slug (1:1000), anti-Twist1 (1:500), anti-ZEB1 and anti-ZEB2 (1:500, Santa Cruz Biotechnology, Santa Cruz, CA). Rabbit monoclonal anti-E-cadherin (1:1000, Santa Cruz). Rabbit polyclonal anti-MDM2 (C-18) (1:500, Santa Cruz). Mouse monoclonal anti- $\alpha$-tubulin $(1: 2000)$ and anti-fibronectin (1:1000) (Cell Signaling, Danvers, MA). Mouse monoclonal anti-N-cadherin (1:500), anti-ZO-1 (1:1000) and anti-vimentin (1:1000) (Abcam, Cambridge, UK). Mouse monoclonal anti-Restin (1:500), anti-His (1:1500) and anti-Flag (1:2000) (Sigma). Mouse monoclonal anti-p73 (1:1000), anti-p53 (1:1000) and anti-p63 (1:1000) (Abcam). Horseradish peroxidase-conjugated secondary antibodies were obtained from Amersham Biosciences. 


\section{Co-immunoprecipitation assay}

Human 293 T cells were seeded onto the 10-cm plates and cotransfected with Flag-tagged Restin and His-tagged p73 constructs using Lipofectamine ${ }^{2000}$ Transfection Reagent (Invitrogen). 2 days after transfection, cells were lysed in precooled RIPA buffer for $30 \mathrm{~min}$ on ice, followed by $15 \mathrm{~min}$ of centrifugation. Cell lysates were precleaned with protein G-Sepharose beads (GE Healthcare) for $30 \mathrm{~min}$ at $4^{\circ} \mathrm{C}$. After centrifugation at $14,000 \mathrm{rpm}$ at $4^{\circ} \mathrm{C}$ for $15 \mathrm{~min}$, cleaned lysates were incubated with either anti-Flag or anti-His antibody on a rocking platform for $4 \mathrm{~h}$ at $4^{\circ} \mathrm{C}$. Protein complexes were immunoprecipitated by incubation with protein G-Sepharose beads for $30 \mathrm{~min}$ at $4^{\circ} \mathrm{C}$ and then washed three times with lysis buffer. Immunoprecipitated proteins were eluted with $50 \mu \mathrm{l}$ of Laemmli loading buffer and separated by $10 \%$ SDS-PAGE. Protein expression was evaluated by Western blot analysis with either His or Flag monoclonal antibodies.

\section{Wound closure assay}

MDA-MB-231 cells were seeded onto 6-cm cell culture dishes at a density of $5 \times 10^{5}$. A wound was incised in the central area of the confluent culture by a $10 \mu \mathrm{l}$ pipette tip. $12 \mathrm{~h}$ after scratch, phase-contrast pictures were taken by a Nikon microscope using a 10x phase contrast objective.

\section{Cell migration and invasion assays}

$2 \times 10^{4}$ MDA-MB-231 or MDA-MB-451 cells resuspended in $200 \mu \mathrm{l}$ serum-free medium were seeded in the upper chamber with serum-containing medium in the lower chamber of 24-well transwell plates (BD Biosciences, San Jose, CA). After $6 \mathrm{~h}$, the experiment was terminated by wiping the cells from the wells with a cotton swab and fixed and stained with $0.05 \%$ crystal violet for $2 \mathrm{~h}$. Matrigel invasion assays were done using the BD BioCoat Matrigel Invasion Chamber (BD Biosciences). The procedures and the analyses were the same as those for the transwell migration assay except for the presence of the Matrigel.

\section{Cell adhesion assay}

96-well cell culture plates were pretreated with $20 \mu \mathrm{g} / \mathrm{ml}$ fibronectin at $37^{\circ} \mathrm{C}$ for $2 \mathrm{~h}$ and blocked with $0.5 \% \mathrm{BSA}$ solution for $1 \mathrm{~h}$. MDA-MB-231 or MDA-MB-451 cells were plated onto 96-well cell culture plates at a density of $1 \times 10^{4}$ cells/well. Cells were allowed to adhere for 30 min, after which the media were removed and nonadhered cells were rinsed away. Adhered cells were fixed with $4 \%$ paraformaldehyde, stained with crystal violet for $10 \mathrm{~min}$ and dissolved in 2\% SDS. The absorbance was measured at $550 \mathrm{~nm}$ with an ELISA reader (Bio-Tek, Winooski, VT).

\section{$\left[{ }^{3} \mathrm{H}\right]$ thymidine incorporation assay}

MCF-7 and MDA-MB-231 cells $\left(5 \times 10^{4}\right)$ (control and Restin overexpressed cells) were seeded onto the 24well plates. $\left[{ }^{3} \mathrm{H}\right]$ thymidine $(1 \mathrm{mCi} /$ well $)$ was added 4 hours before the cells were harvested and thymidine incorporation was measured by scintillation counting (PerkinElmer, Waltham, MA).

\section{Statistical analyses}

Statistical significance of the studies was analyzed by Student's $t$ test. Differences with $P$ values of $<0.05$ are considered significant.

\section{Additional file}

Additional file 1: Table S1. Primers used for quantitative real-time PCR. Figure S1. Western blot was performed to confirm Restin expression levels in Restin overexpressed MDA-MB-231 cells and Restin knockdown MCF-7 cells. Figure S2. Western blot was performed to detect ZEB1 expression levels in cells transfected with negative control and ZEB1 siRNAs. Figure S3. ZEB1 3'UTR activity was determined in HEK293 cells by luciferase reporter assay upon Restin knockdown. HEK293 cells were seeded onto 24-well plates and transfected with ZEB1 3'UTR plasmids and different dose of Restin knockdown lentivirus (si-Restin). Figure S4. mir-200c and mir-141 levels were determined in Control and Restin overexpressed MDA-MB-231 cells by real-time PCR. Figure S5. mir-200c/ 141 promoter activity was determined by luciferase reporter assay. Figure S6. mir-200b/a/429 promoter activities were measured by luciferase reporter assay in multiple cell lines. Figure $\mathbf{S 7}$. Co-immunoprecipitation assay was performed to detect the endogenous interaction between Restin and p73. (Upper panel) MCF-7 cell extracts were immunoprecipitated with mouse IgG or anti-p73 antibody and then blotted with anti-Restin antibody. (Lower panel) Cell extracts were immunoprecipitated with mouse lgG or anti-Restin antibody and then blotted with anti-p73 antibody. Input, total cell lysates. Figure S8. Co-immunoprecipitation assay was performed to detect the endogenous interaction between Restin and p53. MCF-7 cell extracts were immunoprecipitated with mouse IgG or anti-p53 antibody and then blotted with anti-Restin (upper panel) and anti-MDM2 (C-18) antibodies (lower panel). MDM2 p90 is a positive control. Input, total cell lysates. Figure S9. Western blot was performed to detect p73 expression levels in cells transfected with negative control and p73 siRNAs.

\section{Abbreviations}

EMT: Epithelial-mesenchymal transition; ATRA: All-trans retinoic acid; MAGE: Melanoma associated antigen; HMEC: Human mammary epithelial cells; H \& E: Hematoxylin and eosin; RT-PCR: Real-time PCR.

\section{Competing interests}

The authors declare that they have no competing interests.

\section{Authors' contributions}

ZDL, DCJ and ZZL designed the experiments; ZDL, DCJ, JHQ and SY performed the experiments; ZDL, DCJ and MY analyzed the data; ZDL, SDC and ZZL wrote the manuscript. SDC and ZZL have done overall supervision of work. All authors read and approved the final manuscript.

\section{Acknowledgements}

This work was supported by a grant from Henan Science and Technology Bureau (No. 132300410213).

\section{Author details}

${ }^{1}$ Department of Breast surgery, Breast Cancer Center, Affiliated Cancer Hospital of Zhengzhou University, Henan Cancer Hospital, \#127 Dongming Road, Zhengzhou, Henan 450008, People's Republic of China. ${ }^{2}$ Department of Pathogen Biology, Basic Medical College of Zhengzhou University, \#100 Science Road, Zhengzhou 450001, People's Republic of China. 
Received: 7 August 2014 Accepted: 21 April 2015

Published online: 14 May 2015

\section{References}

1. Meek DW, Marcar L. MAGE-A antigens as targets in tumour therapy. Cancer Lett. 2012;324:126-32.

2. Chomez P, De Backer O, Bertrand M, De Plaen E, Boon T, Lucas S. An overview of the MAGE gene family with the identification of all human members of the family. Cancer Res. 2001;61:5544-51.

3. Hou SY, Sang MX, Geng CZ, Liu WH, Lu WH, Xu YY, et al. Expressions of MAGE-A9 and MAGE-A11 in breast cancer and their expression mechanism. Arch Med Res. 2014;45:44-51.

4. Yang F, Zhou X, Miao X, Zhang T, Hang X, Tie R, et al. MAGEC2, an epithelial-mesenchymal transition inducer, is associated with breast cancer metastasis. Breast Cancer Res Treat. 2014;145:23-32.

5. Ladelfa MF, Peche LY, Toledo MF, Laiseca JE, Schneider C, Monte M. Tumor-specific MAGE proteins as regulators of p53 function. Cancer Lett. 2012;325:11-7.

6. Barker PA, Salehi A. The MAGE proteins: emerging roles in cell cycle progression, apoptosis, and neurogenetic disease. J Neurosci Res. 2002;67:705-12.

7. Chapman EJ, Knowles MA. Necdin: a multi functional protein with potential tumor suppressor role? Mol Carcinog. 2009;48:975-81.

8. Haviland R, Eschrich S, Bloom G, Ma Y, Minton S, Jove R, et al. Necdin, a negative growth regulator, is a novel STAT3 target gene down-regulated in human cancer. PLoS One. 2011;6:e24923.

9. De Faveri LE, Hurst CD, Platt FM, Taylor CF, Roulson JA, Sanchez-Carbayo M, et al. Putative tumour suppressor gene necdin is hypermethylated and mutated in human cancer. Br J Cancer. 2013;108:1368-77.

10. Crawford NP, Walker RC, Lukes L, Officewala JS, Williams RW, Hunter KW. The Diasporin pathway: a tumor progression-related transcriptional network that predicts breast cancer survival. Clin Exp Metastasis. 2008;25:357-69.

11. Du Q, Zhang Y, Tian XX, Li Y, Fang WG. MAGE-D1 inhibits proliferation, migration and invasion of human breast cancer cells. Oncol Rep. 2009;22:659-65.

12. Selimovic D, Sprenger A, Hannig M, Haikel Y, Hassan M. Apoptosis related protein-1 triggers melanoma cell death via interaction with the juxtamembrane region of p75 neurotrophin receptor. J Cell Mol Med. 2012;16:349-61.

13. Zhu F, Yan W, Zhao ZL, Chai YB, Lu F, Wang Q, et al. Improved PCR-based subtractive hybridization strategy for cloning differentially expressed genes. Biotechniques. 2000;29:310-3.

14. Zhao Z, Lu F, Zhu F, Yang H, Chai Y, Chen S. Cloning and biological comparison of Restin, novel member of Mage superfamily. Sci China C Life Sci. 2002;45:412-20.

15. Hassan M, Mirmohammadsadegh A, Selimovic D, Nambiar S, Tannapfel A, Hengge UR. Identification of functional genes during Fas-mediated apoptosis using a randomly fragmented cDNA library. Cell Mol Life Sci. 2005;62:2015-26.

16. Fu H, Yang G, Lu F, Wang R, Yao L, Lu Z. Transcriptional up-regulation of Restin by all-trans retinoic acid through STAT1 in cancer cell differentiation process. Biochem Biophys Res Commun. 2006;343:1009-16.

17. Kalluri R, Neilson EG. Epithelial-mesenchymal transition and its implications for fibrosis. J Clin Invest. 2003;112:1776-84

18. Lee JM, Dedhar S, Kalluri R, Thompson EW. The epithelial-mesenchymal transition: new insights in signaling, development, and disease. J Cell Biol. 2006;172:973-81.

19. Kalluri R, Weinberg RA. The basics of epithelial-mesenchymal transition. J Clin Invest. 2009;119:1420-8.

20. Thiery JP, Acloque H, Huang RY, Nieto MA. Epithelial-mesenchymal transitions in development and disease. Cell. 2009;139:871-90.

21. Tam WL, Weinberg RA. The epigenetics of epithelial-mesenchymal plasticity in cancer. Nat Med. 2013;19:1438-49.

22. Polyak K, Weinberg RA. Transitions between epithelial and mesenchymal states: acquisition of malignant and stem cell traits. Nat Rev Cancer. 2009;9:265-73.

23. Gregory PA, Bracken CP, Smith E, Bert AG, Wright JA, Roslan S, et al. An autocrine TGF-beta/ZEB/miR-200 signaling network regulates establishment and maintenance of epithelial-mesenchymal transition. Mol Biol Cell. 2011;22:1686-98

24. Zeisberg M, Neilson EG. Biomarkers for epithelial-mesenchymal transitions. J Clin Invest. 2009;119:1429-37.
25. Vincent-Salomon A, Thiery JP. Host microenvironment in breast cancer development: epithelial-mesenchymal transition in breast cancer development. Breast Cancer Res. 2003;5:101-6.

26. Wu Y, Lu F, Qi Y, Wang R, Zhang J, Lu Z, et al. Interaction of Restin with transcription factors. Sci China C Life Sci. 2005;48:256-62.

27. Yan W, Wang WL, Zhu F, Cheng SQ, Li QL, Wang L, et al. Cloning and subcellular localization of apr-1--a new gene of tumor specific antigen family. Ai Zheng. 2005;24:129-34.

28. Gregory PA, Bert AG, Paterson EL, Barry SC, Tsykin A, Farshid G, et al. The miR-200 family and miR-205 regulate epithelial to mesenchymal transition by targeting ZEB1 and SIP1. Nat Cell Biol. 2008;10:593-601.

29. Wei J, Zaika E, Zaika A. p53 family: role of protein isoforms in human cancer. J Nucleic Acids. 2012;2012:687359.

30. Gurtner A, Starace G, Norelli G, Piaggio G, Sacchi A, Bossi G. Mutant p53-induced up-regulation of mitogen-activated protein kinase kinase 3 contributes to gain of function. J Biol Chem. 2010;285:14160-9.

31. Wang R, Lu F, Fu H, Wu Y, Yang G, Zhao W, et al. Transcriptional upregulation of Restin by p53. Sci China C Life Sci. 2007;50:88-92.

32. Feng $X$, Wang $Z$, Fillmore $R, X_{i} Y$. MiR-200, a new star miRNA in human cancer. Cancer Lett. 2014;344:166-73.

33. Bracken CP, Gregory PA, Kolesnikoff N, Bert AG, Wang J, Shannon MF, et al. A double-negative feedback loop between ZEB1-SIP1 and the microRNA-200 family regulates epithelial-mesenchymal transition. Cancer Res. 2008;68:7846-54.

34. Kim T, Veronese A, Pichiorri F, Lee TJ, Jeon YJ, Volinia S, et al. p53 regulates epithelial-mesenchymal transition through microRNAs targeting ZEB1 and ZEB2. J Exp Med. 2011;208:875-83.

35. Knouf EC, Garg K, Arroyo JD, Correa Y, Sarkar D, Parkin RK, et al. An integrative genomic approach identifies p73 and p63 as activators of miR-200 microRNA family transcription. Nucleic Acids Res. 2012;40:499-510.

36. Chang CJ, Chao $\mathrm{CH}$, Xia W, Yang JY, Xiong Y, Li CW, et al. p53 regulates epithelial-mesenchymal transition and stem cell properties through modulating miRNAs. Nat Cell Biol. 2011;13:317-23.

37. Ridgeway AG, McMenamin J, Leder P. P53 levels determine outcome during beta-catenin tumor initiation and metastasis in the mammary gland and male germ cells. Oncogene. 2006;25:3518-27.

38. Hansen JE, Fischer LK, Chan G, Chang SS, Baldwin SW, Aragon RJ, et al. Antibody-mediated p53 protein therapy prevents liver metastasis in vivo. Cancer Res. 2007;67:1769-74.

39. Powell E, Piwnica-Worms D, Piwnica-Worms H. Contribution of p53 to metastasis. Cancer Discov. 2014;4:405-14.

40. Chari NS, Pinaire NL, Thorpe L, Medeiros LJ, Routbort MJ, McDonnell TJ. The p53 tumor suppressor network in cancer and the therapeutic modulation of cell death. Apoptosis. 2009;14:336-47.

41. Soussi T. p53 alterations in human cancer: more questions than answers. Oncogene. 2007;26:2145-56.

42. Irwin MS, Kaelin WG. p53 family update: p73 and p63 develop their own identities. Cell Growth Differ. 2001;12:337-49.

43. Muller PA, Vousden KH. p53 mutations in cancer. Nat Cell Biol. 2013;15:2-8.

\section{Submit your next manuscript to BioMed Central and take full advantage of:}

- Convenient online submission

- Thorough peer review

- No space constraints or color figure charges

- Immediate publication on acceptance

- Inclusion in PubMed, CAS, Scopus and Google Scholar

- Research which is freely available for redistribution 